\title{
The role of intergenerational relationships in challenging educational inequality: improving participation of working-class pupils in Higher Education
}

\author{
Katie Hunter, Alastair Wilson \& Katherine McArthur \\ School of Education, University of Strathclyde, UK
}

\begin{abstract}
Analysis of data on school leavers in the UK points to considerable inequality in access to higher education. This is particularly acute in Scotland where access to the most competitive courses remains extremely difficult for those young people who are first in their generation to try and enter university or from low-income households. Programmes to address this issue have had varied approaches framed around policy ambitions to 'close the attainment gap' or 'raise aspirations'. However research has argued that these approaches have largely conceptualised the problem at an individual rather than structural level (Cummings et al., 2012; Gorard, Beng, \& Davies, 2012). Glasgow Intergenerational Mentoring Network is an ongoing research and development project which recruits retired professionals as volunteer mentors and matches them with 15-18 year old secondary school pupils from lower-income areas of the City. This paper draws from research within this project to demonstrate the difficulties these young people face surrounding their interaction with very different social and cultural worlds, of which they have limited understanding and very restricted access. The paper illuminates the crucial role that intergenerational relationships can play in supporting young people in their journey into higher education. These are roles that, collectively, are enabling more young people to move into university and professional careers and through increasing social mobility are challenging inequality.
\end{abstract}

\section{Introduction}

In the UK, recent statistics published by the Sutton Trust (2016), highlight the need to address greater equity in access to higher education. In Scotland where this problem is particularly acute, 17-18 year olds from the most advantaged areas are more than four times more likely to go straight to university than those from the least advantaged areas (Hunter Blackburn, Kadar-Satat, Riddell, \& Weedon, 2016). In addition there are concerns about the 
limits of social diversity in the top Scottish professions. The Social Mobility and Child Poverty Commission (SMCP) highlight that "43 per cent of people at the top of Scottish society studied for a first degree at one of the four ancient universities in Scotland. This includes 66 per cent of senior judges, 50 per cent of top media professionals and 46 per cent of Scottish MPs" (SMCP Commission, 2015, p.178). Alan Milburn, chair of the SMCP Commission has warned that "there is a risk that Scotland sleepwalks into a social mobility crisis unless urgent action is taken" (SMCP, 2014). Iannelli (2011) further asserts that the recorded rise in participation at Higher Education among underrepresented groups can be attributed to the increase in participation by people from disadvantaged backgrounds in new universities and Further Education colleges. She concludes that class differences have persisted, in that educational expansion has "not translated into any break with the patterns of social inequalities in the chances of entering the top-level occupations" (p. 251).

Educational research in the UK exploring this issue from a sociological perspective, has not been extensive and arguably drawn from limited theoretical perspectives. That which is available has drawn heavily from the work of Bourdieu and particularly ideas around social and cultural capital in its interpretation of individual trajectories (Wilson, Hunter, Spohrer, Brunner, \& Beesley, 2014; Archer, Hollingworth, \& Mendrick, 2010). However there is some research that contextualises this issue and provides a more critical understanding at community and societal levels (Schuller, Baron \& Field, 2000). In a detailed longitudinal study of Chicago Schools, Bryk et al., (2010) identified the role played by the both access to and utilisation of social capital in the improvement process of Chicago schools. Specifically they looked at the role played by both bonding and bridging capital in the process of school improvement which they define as follows:

Bonding social capital focuses on the density of supportive social ties within a neighborhood or community. The existence of such ties affords group solidarity that makes achieving collective goals much more likely [....] In contrast, bridging social capital accrues in disadvantaged communities as residents have opportunities to engage with external individuals and organizations (Bender Sebring et al., 2006, p.35)

The results were significant and pointed towards the value of both forms of capital in supporting effective school development and more positive outcomes for pupils. Of particular interest is their analysis of bridging capital in which they are able to show that access to and therefore effective use of this form of capital was particularly difficult for those schools in areas of high social and economic deprivation. 
In parallel with this research but without an explicit focus on education, other theory has explored stratification and inequality in society. In particular research has drawn on a life course paradigm which has focused on '... differentiating within-individual change across the individual life course and across birth cohorts and/or periods' (Lynch and Brown, 2011). Emerging from this has come an understanding of the ways in which inequality can persist and indeed be magnified over the life course. This 'cumulative dis/advantage' perspective illustrates the ways in which differences in socioeconomic status and early educational attainment can form the basis of inequality that will persist and grow over the life-course (Dannefer, 2003). Building on this, Ferraro and Shippee (2009) argued for the 'Five axioms of cumulative inequality (CI) theory'. In their analysis, the life course trajectories of individuals are influenced by '..early and accumulated inequalities' but that '...these can be modified by available resources, perceived trajectories, and human agency' (p.2). These trajectories are observable in the unequal opportunities that materialise for young people in terms of access to professional careers. These arguments resonate with recent work in the UK on social class by Savage (2015) which focuses on the rigidity of social networks and the ways in which these are linked to occupational hierarchies. Savage draws on data from the Great British Class Survey to argue that the individual in the UK maintains a relatively rigid social position in which their social ties and connections are centred around those in their immediate social position (e.g. professional, skilled manual or unskilled).

This paper draws on research undertaken within the development of the Intergenerational Mentoring Network ${ }^{1}$ which explores the ways in which intergenerational relationships have the capacity to disrupt these patterns. It discusses the potential of intergenerational work to strengthen the social and cultural capital of young people, their schools and eventually communities. The research extends from a preliminary study focusing on school management attempts to create a 'bridging' institution between what could be seen as a distant and somewhat alien educational system and the local community (Gillies, Wilson, Soden, Gray, \& McQueen, 2010), As we progress intergenerational mentoring it is clear that there is potential for mentors to be a vital source of bonding capital, but perhaps more critically bridging social capital for schools and individual pupils.

\footnotetext{
${ }^{1}$ Intergenerational Mentoring Network is a 3-year research and development project funded by the Big Lottery developing mentoring support to young people across 6 urban schools in areas of high economic and social disadvantage.
} 


\section{Positioning mentoring}

Raffo et al., (2009) view that one of the major problems for policy dominated by a culture of performance monitoring and outcomes, is a tendency to look for pointers to action that incorporate more straightforward ways of understanding complex issues related to equity and opportunity. In the UK, Perry \& Francis (2010) indicate that policy inspired interventions to address the class-gap in education have maintained an enduring focus on 'poverty of aspiration'. A range of research now argues that policy which supports interventions to 'raise aspirations' is significantly flawed and, furthermore, re-enforces a deficit model of young people and their families in which they are viewed as having intrinsically low aspirations for their future careers (Gorard, Beng \& Davies, 2012; Cummings et al. 2012).

Research in the UK by Archer, Hollingworth \& Mendick (2010) recognise that a more nuanced approach to careers information and advice is needed, in which young people are supported in their knowledge and understanding of different career routes. In a study of 89 young people from London described as 'at risk of dropping out of education', Archer et al. found that a substantial number of the young people held, at some part in the course of the study, aspirations to become professionals. The authors emphasised the ways in which these young people regularly adapted and tempered their aspirations which were '...circumscribed according to their structural locations' (p.84). A study by Kintrea, St Clair, \& Houston (2011) of disadvantaged young people living in Nottingham, London and Glasgow found that young people do have aspirations to go on to university and to attain professional and managerial positions. Their research concluded that policy needed to pay greater attention to the barriers young people experience in realising their aspirations and, crucially, that this should be sensitive and adjusted to the issues facing young people at local community levels.

Studies in the US have highlighted the in depth nature of navigating the process of college applications, and recognise the role that schools play in supporting these processes. Roderick, Coca, Moeller \& Nagaoka's (2008) research compares guidance and resources in relation to 'college-going cultures' across schools. They describe the importance of strong college-going cultures, concluding the importance of social networks in supporting young people with their future learning plans as knowledge and understanding takes place between people. They recognise that decision-making about post-compulsory education involves a range of activity 
and builds on previous research that finds that low-income, first-generation students are particularly likely to encounter problems such as submitting applications on time, applying for financial aid, gaining acceptance, and enrolling in college.

Within this context, mentoring programmes have emerged to support pupils from workingclass backgrounds navigate an increasingly complex post-compulsory education sector. Evidence from the US, where mentoring is much more fully established on the educational landscape, points to a variety of different forms spanning youth, academic and workplace mentoring (Eby, Allen, Evans, $\mathrm{Ng}, \&$ DuBois, 2008) and with mixed evaluations of impact. School-based mentoring programmes in the US targeted at socially disadvantaged young people vary from those employing peer mentors and older students to adults of different ages, and show modest positive impacts on outcomes such as truancy, misconduct and academic abilities (Rhodes, 2005). A meta-analysis of 73 US mentoring programmes (DuBois et al., 2011) suggested overall effectiveness, showing positive outcomes for young people across social, emotional, academic and behavioural domains, and positioning mentoring as having equal effectiveness compared with other forms of youth intervention.

In a broad study of mentoring, Abelev (2009) examined the experiences of 48 people who were first generation college students (the first to attend college in their families), half of whom had progressed to college and half who were established professionals. Aspects of the main findings are particular to the US; some participants were supported in their application to non-local higher performing schools, some received financial support from their mentors, or had personal educational plans drawn up by their mentors. Abelev though located the success of participants in the influence of their mentor:

...understanding of this milieu was fostered through an ambassador-like mentor from the middle class that both accessed the resources and, by doing so, indirectly and directly taught the respondent the necessary interactional pattern. The mentors' knowledge of the interactional style and how to access resources at critical institutions, and the expectation that the child was entitled to that resource, was important to the process of advancement for each respondent (p.135).

Abelev draws heavily on the Bourdieu's concept of habitus to help understand the experiences of participants, defining it as '...the norms, beliefs, speech patterns and 
interactional style that members of a group internalize and accept as doxa, or truth, and then view as common sense, or the way things should be done' (p.135). He argues that one of the main areas in which the difference in habitus between socially advantaged and disadvantaged young people manifests itself is in their interaction with institutions. As a result of their habitus, socially disadvantaged young people inherit what is effectively an interactional deficit which complicates and frustrates their interaction with schools and other powerful educational institutions. Ultimately this restricts their opportunities and, '...as a result, children outside of the middle class do not gain access to important knowledge and resources necessary for manouvering within the middle class' (p.134).

In the UK there has been an increasing development of mentoring related activity which has evolved in a variety of forms. Perry and Francis (2010) caution that mentoring schemes may by their nature be 'top down' and fail to pay attention to the educational engagement of working-class young people. They argue that "few programmes accentuate the mutual learning and benefits resulting from social-mixing, mutual understanding and shared purpose" (Perry and Francis, 2010 p.17). In programmes designed to widen participation to higher education, Kezar (2011) also cautions against interventions intending to provide lowincome students with the social capital missing from their environments. These argues Kezar may be based around over-simplistic transmission models of capital which are likely to have limited impact (pp.251-2). To avoid a deficit understanding of young people, their families and schools, interventions are needed which build programs based on the experiences of lowincome students, rather than simply the experiences and knowledge of middle-income students (Coylar, 2011). In consideration of intergenerational mentoring as a useful addition to the field of Widening Participation, Wilson et al., (2014) illuminated the ways in which mentors can facilitate an awareness and deeper understanding of complex social circumstances. Their research further suggested that engaging with mentoring as an intervention from a research and development perspective provided a means of illumination of the the broader structural explanations of young people's difficulties. The following section will explore the potential for intergenerational mentoring as a means of addressing these concerns, with the intention of evolving a form of mentoring that is both grounded and effective. 


\section{Developing a model of intergenerational practice}

The Intergenerational Mentoring Network evolved from a partnership with practitioners in a school (located in an area of high social and economic deprivation) and researchers within the School of Education at the University of Strathclyde. The project began as a means to provide extra support to pupils seeking to be first-generation entrants to university. The initial phase of the work identified that the young people had limited understanding of the professions and lacked access to social networks that could facilitate career understanding, work experience and knowledge of higher education. A one-to-one mentoring programme was initiated. Mentors were recruited from within the University lifelong learning department and the Alumni. This provided a mentor cohort of largely middle-class professional retirees who were matched with pupils around subject and career interests. The mentors and pupils established weekly/at times fortnightly meetings. Considering the time needed for mentors to travel to and from the school and to conduct the necessary research to support their mentees, the time commitment from each mentor was close to one half day per week (see Wilson et al., 2014). The project mapped on to existing school management practices that seek to identify and support young people who, based on their 4th year exam results at aged 15 and 16 years old, have the potential to enter higher education. Mentees were those young people identified by the school as having the potential to gain 5+Higher examinations (the benchmark for entrance to higher education in Scotland) and to be interested in applying for a place in higher education. Typically this varied between 15-20 pupils in a year group of approximately 150 .

\section{The Research Study}

From the outset the project was funded as an iterative process of research and development. A small team of researchers were responsible for all operational aspects of the project including recruiting mentors and supporting mentoring relationships. In addition, the research team were involved in the following data collection procedures which included: conducting interviews with key informants, mentors and pupils; collecting reflective notes from mentors; collecting written accounts from pupils and collation of researcher notes based on meetings and observations. In this way, data collection in the project was ongoing and the research generated an extended narrative and genealogy of mentoring relationships. These formed part of an overall iterative process of research and development that enabled the project to 
develop based on emerging findings. The following research questions shaped the development of this process:

How is the project experienced by all participants?

In what ways does it impact on their lives?

If appropriate, what processes need to be developed to expand the project and how do these need to be shaped and improved?

- How can the overall impact of the project be assessed?

In moving through the different phases of the project, the research and development process provided an opportunity to develop an effective mentoring programme by examining its processes and impact. It also facilitated an in depth and ongoing thematic analysis of the situated and socially negotiated nature by which young people acquire the necessary economic, social and cultural capital in order to progress an application to higher education courses. This research paper builds upon research questions 1 and 2 and focuses on specific dimensions of intergenerational practice to understand the experience of participants.

\section{Exploring an intergenerational dimension to mentoring: Key findings from the project}

The following sections of the paper present key thematic areas in the form of a series of vignettes. Case studies of mentoring relationships are presented which draw on researcher notes, interview data, mentor notes/reflections and email correspondence between the research team and participants. The fourth case study draws from a longitudinal account of a young woman's experience of intergenerational mentoring over a period of 6 years.

Orientating towards university and gaining an understanding of a profession.

The initial phase of the project explored the young people's social networks (Wilson \& Hunter, 2011). One striking finding of this research was the unfamiliarity the young people had with higher education and the lack of personal contacts that they could draw on to help them access knowledge about higher education and routes into subsequent employment. For example, when looking at the networks of family and friends of 26 young people in the study group, only one young person had a parent who had a degree level qualification. Another key finding was the way in which the idea of continuing to study at university emerges relatively late in that young people tended to make decisions about staying on at school and studying for Highers after obtaining their exam results in S4 (aged 15-16) (see also Wilson et al., 
2014). One important role a mentor tends to play is familiarising young people with the range of university course and subsequent career landscapes. This is exemplified by the following account of mentoring.

Stephen, a young man who was initially considering pursuing a career in architecture or civil engineering, was matched with Joan, a former architect who also ran writing courses for architects, engineers and other construction professionals. When asked about his interest in this career area, Stephen said that he "didn't want to work in an office" and that he "wanted to build something big". He qualified this with:

I wanted a degree that would guarantee me an actual job. Law - everyone needs a lawyer right? and even in the recession. That's why I was thinking maybe engineering or architecture, cos I like maths and physics, and it's pretty necessary (extract from interview with pupil).

Stephen's mentor embarked on a process of helping him link his interests and academic abilities with wider ideas about employment in order to help him make an informed decision as to whether he should study architecture or engineering:

I explained to Stephen that I'm giving him articles that are meant to be food for thought because it's really important that he has his own thoughts/ideas/ideals about architecture for a number of reasons. First, so he knows in his own mind that he's committed to pursuing a career in architecture. Second, to help him decide which architectural school would best suit him. And, third, to help him make strong university applications and do well at interview. I emphasised that it isn't necessary for him to have any particular interests or views, but that he really needs to have interests and architectural passions of some sort (extract from mentor notes).

In addition to these reading activities, Joan encouraged him to engage with the built environment around him. Initially she deliberated about whether she should encourage him to explore flagship projects in and around the City. She held back thinking about the travel costs that Stephen might incur and also recognised that his confidence in travelling around the City was fairly limited. Instead, she began by encouraging him to look at local building projects and research which architects and engineering companies were involved. She also described some historic engineering advances that were made in the building of a block of high-rise flats in which Stephen had previously lived. On one occasion Stephen showed Joan some pictures of buildings he had taken on a family holiday. They discussed these at length 
and she encouraged him to print them out and begin an annotated book, highlighting that this was a practice which architect students engaged in at university. She also encouraged him to start adopting other skills that were useful in Engineering and architecture, particularly sketching. Joan was initially a little frustrated at Stephen's lack of enthusiasm in adopting this practice, the research team suggested that she incorporate this activity into a mentoring session. Joan brought in sketching materials and objects and they spent time sketching and discussing why this activity was useful. Joan also spent time discussing changes to the industry as a whole and in more detail the different types of architecture and engineering firms and practices:

I've talked about the difference between architects and engineers .... I think when I started working in this industry a whole range of not tiny, but companies that were $40,50,60,150$ engineers or consultants, gradually amalgamated. So actually on the engineering side, there are a lot more vast international companies, whereas although that's happened a bit in architecture it's not so much. So I just kind of encouraged him to think a wee bit about that, and kind of imagine the sort of working environment that he'd like to be in (extract from mentor interview).

By the end of their school year of mentoring, and leaning more towards architecture Joan drew on her contacts to organise a week's work experience placement for Stephen in an architect's office:

He really enjoyed his work experience at [name of practice]. They set him a project based on a real competition brief for the design of some trekking cabins. He enjoyed doing research for the project and learning to use SketchUp software. He also went on a site visit to a nearly completed building and was able to join in the social life of the office - including a small leaving party for one of the staff members on what was also his last day. It sounds as though the experience has helped to confirm his decision to study architecture, although he still hasn't ruled out related subjects (extract from mentor notes).

Reflecting on this experience Stephen said that he hadn't realised that architects offices were all computer based and realised the need to learn computer software. In order to support Stephen with entry to the course, Joan also used her contacts in architecture schools to find out about the level of preparation needed to apply for the various courses. She obtained details about a portfolio preparation course and helped Stephen enrol. She is currently supporting Stephen through his final year at school and helping him make the most of preparatory experiences. 


\section{Nurturing learning}

As the above account demonstrates mentors can provide a level of intellectual engagement and exposure to learning with which the young people are perhaps unfamiliar. The essence of this academic support is rarely considered 'tutoring' however, mentors tend to display a level of confidence in supporting pupils with academic work. The following extract from a case study illustrates how the knowledge and experience that mentors have acquired over their lifetime becomes critical in supporting Hannah, a pupil wishing to progress an application to medicine.

Gillian, a retired physician recognised Hannah adopted a very technical approach to studying and completing coursework. She recognised that Hannah needed to be equipped with a broad subject knowledge base and that an approach to understanding the world around her was essential if she were to progress into university and on to a career. In particular, Gillian recognised that Hannah's competence in English language could present an obstacle to being considered for medicine. Gillian took an interest in supporting Hannah in ways that could strengthen her position in this area. She supported Hannah in in developing her critical thinking; presentation skills; understanding of English Literature and Language and helped expand her general knowledge. To assist with this Gillian brought copies of the British Medical Journal and broadsheet newspapers to each mentoring session. Time was spent browsing publications and finding articles of interest that were used to facilitate topical conversations on health related subjects and general knowledge:

We have explored broader issues, usually centred around an article in the Guardian or BMJ [British Medical journal]: e.g. some graphs about comparative unemployment rates, differences in proportion of GDP spent on health in G20 nations, and how outcomes in health can be measured. The plan from New York to limit the size of fizzy drinks that can be served in food outlets was of interest. We have also worked on vocabulary from a number of articles. Hannah was reasonably well informed about American elections (extract from mentor notes).

Another strategy of Gillian's was to introduce Hannah to contacts that could both support different aspects of her studies but also provide her with exposure to individuals with a range of professional knowledge and varied learning experiences. She introduced Hannah to her husband, a retired statistician who was also a mentor. He provided Hannah with some additional maths tutoring and supported her preparation for the UK Clinical Aptitude Test 
$(\mathrm{UKCAT})^{2}$. Gillian introduced Hannah to another friend, a retired chemistry lecturer whose wife was a GP and who supported Hannah with some additional chemistry tutoring. A further friend of Gillian and her husband was a retired GP but who had an interest in economic history and French. As well as helping Hannah with conversational French he spent time discussing the book he had written on Glasgow's economic and social history. Gillian's senior level professional experience and standing in a number of voluntary positions in the field of medicine conferred several further advantages in her role as mentor. In addition to organising voluntary work experience placements in different specialities with former colleagues, Gillian facilitated Hannah's attendance at symposia at the Royal College of Physicians and Surgeons as a means of familiarising her further with the profession. The above account highlights the breadth and depth of academic support and experiences that mentors are able to draw on through their own subject knowledge and interests. It also illustrates the availability of networks that they are able to mobilise to further support pupils like Hannah.

\section{Providing emotional support}

Another dimension we have identified in intergenerational practice is the way in which some mentors draw on their own experiences as first generation entrants to university and progress within their professional careers. This may be further informed by their experience of supporting their children or younger people from among their own networks. In the following section, Mike, a senior academic explains how he thought he had been useful to Jane, a pupil interested in a career in teaching.

I kind of feel I've been useful in some senses ... occasionally just prompting and trying to get her think about things a little bit more, get her to reflect a little bit more. The kind of things I would have liked when I was a teenager, if someone had been there to actually maybe do that for me, my parents didn't have that background (extract from interview with mentor).

Mike was equipped to help Jane formulate a strategy to support her application to university. Jane achieved 4As and a B in her Higher examinations at the end of S5. She completed her sixth year studies and is studying English and Theatre Studies at University with a view to

\footnotetext{
${ }^{2}$ The UK Clinical Aptitude Test (UKCAT) is a test used in the selection process by a consortium of UK university Medical and Dental Schools
} 
progressing towards teaching. However during her first term in S5 (aged 16) she recalls that she had considered leaving school:

It was the end of October and it was getting to the point where the teachers were like "you've got prelims in a month - it's time to knuckle down", and I was just like 'woah, what's going on?' So I applied for an apprenticeship and I got in, for childcare (laughs). I can't believe I did it now that I think back... I genuinely believed I wasn't going to do well (extract from interview with pupil).

Mike facilitated a number of opportunities to help Jane learn more about her chosen profession. He arranged a visit to the university to meet colleagues who taught on the postgraduate diploma in education (PGDE) and organised for her to attend a teaching day with PGDE students who were reflecting on their school placement experiences. He organised some additional work experience in a school and emphasised the importance of achieving National 5 maths, something which Jane struggled with and had not realised was necessary. He also advised her to consider diversifying from Drama teaching to include English teaching as this would enhance her career prospects. Whilst these provided valuable insights into teacher training and helped increase future opportunities, Jane felt that getting to know Mike had played a key part in her progress.

I don't think I would be here, genuinely don't think I would be here if I did not have Mike helping me. I think I would be in a different uni, doing something that I didn't want to do -like genuinely.

(Interviewer) So what is it that you think Mike helped with?

Like trust. Like I trust Mike, so after meeting him and getting to know him, he told me about him, where he came from, how he got into what he's done, and what jobs he's done and that kind of thing. And I know that he was experienced and he knew what he was talking about, and that gave me a sense of security so I knew that what he was saying like - was a good course of action because that kind of sense of security is important...because, that time of $5^{\text {th }}$ year is such a confusing and really really really scary year (extract from interview with former pupil).

This level of emotional support and encouragement is typical of mentoring relationships, and in some cases may be more of a focus due to the particular needs of the young person involved.

James, a retired lecturer in earth sciences was matched with Kim, a young woman who had initially thought about studying medicine, but decided against that and said instead she wanted to be a florist. In getting to know Kim, James discovered that she was interested in 
biology but was allergic to animals so considered working with plants as an only option. Soon after their first meeting, James was alerted to the fact that Kim had been having regular panic attacks at school:

One of the teachers said to Kim when I was sitting beside her, "have you told James about the panic attacks?" otherwise she wouldn't have talked about them. When I said "why have you not been using some of the resources at school - counselling or something like that?", she said "James, in this school, most of the people here have really big problems. Mine is just a wee one" (extract from interview with mentor).

The attitude to help-seeking that Kim demonstrates is not unusual, but it is worth noting the context in this case. The school serves an area with high crime rates, low life expectancy, poor health and poverty. While Kim's opinion is self-effacing, it is also astute when viewed in context. James advised Kim that while it was her own decision not to make use of the school counselling service, he felt it important to acknowledge that her problems were not insignificant, saying "we care about you, and this needs to be addressed, we need to think about dealing with it" (extract from interview with mentor). James, though not himself providing counselling, supported Kim to cope with her anxiety in the absence of professional help. He was in turn supported by regular conversations with a member of the research team with experience of both secondary school counselling and providing counselling supervision. This arrangement allowed James to explore and discuss his mentoring relationship with Kim.

James noted the intersection between mental health and social disadvantage based on his experience of working with Kim. He compared his mentoring experience with personal experience of his niece who was the same age as Kim and experiencing similar anxiety issues. He recognised that feeling unprepared for any situation led to anxiety and for both young women, the focus of which was on school work and academic pressure. James felt that Kim's situation was exacerbated because the school did not have the necessary text books to prepare pupils adequately for their Higher exams. He felt that if this situation had occurred when his own children were at school, parents would have complained or he would have bought the books. In suggesting the idea to Kim she came back to the next session saying that her mother, who worked night shifts in retail, might be able to buy them at the end of the month when she got paid. 


\section{Drawing on networks}

As the project developed, the research team became cognisant that supporting pupils as they progress towards, particularly highly competitive courses, necessitates a more networked approach. This is demonstrated in the following case study of Emma, a young woman and her progress into a career in law. When the research team initially met Emma in S5 (aged 17), she described that her friends were a big influence in terms of staying on at school:

I probably wouldn't be doing 5 Highers if I hadn't started hanging around with them. I was sort of on track for like passing 3 of my Standard Grades before that. And then, I ended up being on track to pass all of them... I kind of didn't really bother and when they're bothering I've got nothing else to do so - I may as well study (extract from interview with Emma).

Emma and one of her friends were thinking at this point to apply to study medicine, dentistry or veterinary medicine. Emma initially worked with a member of the research team, who provided some help with English, and also met regularly with Gillian and her husband who were mentoring her friends. Recognising that both Emma and her friend did not have any experience of the medical profession, Gillian suggested that they sign up for a range of extracurricular activities including a first-aid course with St Andrew's ambulance. Gillian also identified a widening access programme designed to support young people from low income households gain entry into dentistry. Whilst Emma's friend was making steady academic progress, Emma struggled with Chemistry and at the end of S5, having completed her Highers, she decided instead to study law. Emma was due to begin work experience in a dental practice so she let her friend take this opportunity instead. Emma, helped by her friend, started looking for some work experience for Emma in a lawyers' office. They did this by dropping into city centre offices and asking if there were any opportunities available. Finally, Emma secured a week's work experience in a law firm through a friend of her father. In S6 Emma was matched with a mentor, Helen to support her studies in Advanced Higher English. Having geared her S5 year towards studying sciences, Emma had not performed well enough to be considered for law schools at those universities regarded as being more prestigious and that asked for $5 \mathrm{As}$ in one exam sitting. Emma identified a law course in another city which had lower entry requirements and was successful in her application.

Emma worked for a bank throughout her degree studies and commuted to university in a different city. She stayed in touch with the research team member, meeting up for coffee and 
on some occasions asking for help with proof reading her assignments. Meetings became more regular during $4^{\text {th }}$ year of her degree as she encountered several challenges. On track for a good degree, she was struggling to manage the relationship with her dissertation supervisor. Emma was supported in constructing emails to her supervisor asking for help and followed advice to speak to her tutors.

Emma was also applying for internships (generally a two week placement) and traineeships (1 year placement required in order to practice law). The researcher supported Emma in generating material for answers encountered on application forms and helped her think about tailoring answers for particular law firms. Emma completed around 20 application forms and received rejections from all of them.

Most law firms will reject applications with no feedback, meaning there is no prospect for modifying your applications to make them better as a result of their suggestions. I didn't really know what they were looking for (extract from Emma's reflective account).

Unable to secure any kind of placement, she looked for work experience that she could fit in around the demands of studying and employment. Through a contact of her friend's aunty, she was able to undertake some ad hoc work experience with a local solicitor. Emma realised that this opportunity, whilst she could add it to her CV, did not enhance her prospects of finding a traineeship as it was limited in terms of making industry contacts. She began to worry about the costs of furthering her studies:

The diploma costs between $£ 6500-£ 7500$ and is only part funded by SAAS$£ 3400$ loan. This means I have to provide the rest of the fee before they undertake the course and the diploma only lasts for 2-3 years in which time you have to find a traineeship. If you do not find a traineeship the diploma expires, although I think the Law Society can extend this (extract from Emma's reflective account).

Unsure of how to progress, Emma talked about applying instead for an MSc in Law at a cost of $£ 4000$ with the idea of possibly studying for a $\mathrm{PhD}$ and progressing into lecturing instead of practising law. The research team began, on Emma's behalf, to make enquiries among the network of mentors with regard to help finding an internship or traineeship. They also contacted John, a retired lawyer who Emma had briefly been introduced to through the project when she was in final year of school. The research team updated John on Emma's progress and he advised her to apply for an internship and traineeship at a law firm on which he was a board member. He also referred Emma's case to contacts in the Law Society as he 
knew they were keen to support young people from lower-income backgrounds. Emma's meeting with a member of the Law Society encouraged her to proceed. He offered to read her covering letters and CV and suggested various smaller law firms to contact.

Emma's confidence to continue grew further when she was selected for a 2 week paid internship following John's intervention. Following this placement, she was invited to undertake some paid employment for one of the clients she had met. Emma started the diploma with five weeks paid work experience and a $£ 2000$ scholarship from the university. Two months into her diploma course, Emma was invited to interview for the traineeship position. She contacted the careers service at her University to organise a mock interview but was told they were fully booked. The research team asked if anyone from among the wider mentor network could help. A new mentor, a retired solicitor, agreed to meet with Emma and they spent around three hours preparing for the interview situation. Emma was not selected but received constructive feedback from the interviewer who had also supervised her summer internship. She was told that she had performed well but on this occasion had been unsuccessful. The interviewer however asked if on Emma's behalf, she could recommend her to two further law firms. Through this process of networking, Emma is awaiting to hear if any traineeship opportunities are available. She continues to submit applications and participate in further work experience alongside her job in a bank and Diploma in Professional Legal Practice.

\section{Discussion}

The above accounts highlight that mentors with a breadth of industry experience and established contacts are able to assist young people with a necessary conceptual orientation towards a career. They also present the role that mentors can play in introducing school pupils to new environments, resources and experiences essential to their understanding of different careers. This grounding and orientation was richly available from mentors with accumulated professional experience, contacts and access to well established professional and social networks. Stephen's mentor, for instance, was able to equip him with a more nuanced understanding of his chosen career area to support a more in depth and informed decisionmaking process. This involved providing knowledge of a changing industry which gave Stephen a more informed knowledge of the profession. It was further achieved through their on-going discussions and was supported by the reading material that she brought to their 
mentoring sessions. Joan was also able to draw on her contacts to introduce him to a professional work environment. This experience provided the necessary exposure to a range of professional practices and resources that were previously unknown to him such as the industry computing software and the social nature of some architect firms. Likewise Gillian equipped Hannah with a more in depth understanding of medicine by introducing her to a range of reading material and a network of people with very broad experience in the medical profession. Mike provided Jane with opportunities to learn more about teaching through his introductions to colleagues and current university students. He also provided the necessary knowledge she would need for an eventual application to teaching at postgraduate level. The necessity of access to professional networks is evident in Emma's transition as she progresses her studies beyond degree level. These findings highlight that mentors provide a considerable learning experience that facilitates their mentees understanding of and engagement with subject areas and careers.

However the findings also illustrate that delivering this focused support was something that the one-to-one mentoring relationship made possible. The mentors were equipped to react to the immediacy of young people's situation because they had the ability to recognise and objectify the different challenges facing the young people. With support from the research team, Stephen's mentor recognised his hesitancy in adopting practices such as sketching, the need for which, and benefit of, was not immediately apparent to him. To nurture this activity she devised a task which they could work on together which provided an opportunity to focus on the explicit nature of this skill, and allowed for a more practical engagement with studying architecture at university. Likewise Gillian equipped Hannah with a more in depth understanding of medicine by introducing her to a range of reading material and planning her introduction to a network of people with varied experience in the medical profession. She supplemented this by planning experiences such as visits to the Royal College of Physicians and Surgeons. This exposure in particular was identified by Gillian as crucial. She felt it could expose Hannah to the elite nature of the profession and individuals with whom she would have had no or very limited social contact. This exposure to and learning from their mentor and wider sources is something that was critical to the young people. It provided the knowledge and understanding necessary for a successful application to university and, potentially, the first step on the path to previously elusive careers. 
These activities were planned and delivered within a close one-to-one mentoring relationship established from weekly meetings. Mentors played a vital role in recognising times when supporting the emotional well-being of young people was just as critical. Mike, for example, is able to react calmly and confidently to Jane's immediate situation and emotional difficulties. The data highlights that a trusting relationship developed in which Mike drew on his personal journey of social mobility. This helped to minimise uncertainty for Jane around education and the transition to a career. The data highlights the range of processes through which Emma was supported and which became essential in sustaining her confidence to proceed within the profession. As she neared the end of her undergraduate course, Emma was supported in her confidence to construct emails and address written correspondence to tutors and prospective employers. 'Getting on' with this, was crucial as Emma, faced with a large amount of uncertainty around financing further academic qualifications and securing training opportunities waivered in her commitment to continue to pursue law as a career. Through mentoring she gained confidence from developing knowledge of processes such as constructing written correspondence and networking with industry contacts.

The research recognises that the development of ongoing, supportive, mentoring relationships are able to respond to a range of emergent circumstances. They play a significant role in helping young people overcome their practical and emotional needs throughout an unfamiliar and at times daunting process. Delivering this type of support is not unproblematic and further work within our project will explore this dimension. Our previous research highlights that being 'intergenerational' may not be simply a sufficient attribute to support these young people and that mentors come to the project equipped in different ways and in need of different levels of support (McArthur, Wilson \& Hunter, 2016). Future research will explore the impact that this role has on mentors in terms of the rewards and challenges they experience and how, as a project, we can continue to provide support to intergenerational mentoring relationships.

These findings expose some of the conceptual limitations in conventional approaches to delivering information, advice and guidance for high-attaining school leavers who are first generation entrants and/ or from low income households. Perceiving these young people to be in need of more information and advice is not an adequate response to their needs. Our research shows that movement between social classes in Scotland, as represented by entrance 
to some of the most competitive courses in higher education, depends not just on access to information but on the effective operationalization of different forms of social and cultural capital. This, we argue is where intergenerational mentoring makes a crucial contribution, effectively providing the bridging capital that these young people have such limited access to. We have shown some of the mechanisms that guard access to professional networks described by Savage (2015) such as the ability to navigate and orientate towards a profession, to locate knowledge and understanding of a profession in a broader context and to identify and draw effectively on social networks for support. Disrupting the status quo in this way however is not a straightforward process and involves operating in an educational/social arena that is far from neutral. The intergenerational dimension is important here as mentors were much more than conduits of capital. Their accumulated knowledge and experience of careers was vital but equally crucial was their ability to recognise their mentees vulnerabilities, needs and steer them towards new understanding. Perhaps in this way intergenerational mentoring can bring to focus ideas around social and cultural capital and the relationship of these to cumulative inequality. Through increasing the young people's access to new forms of social and cultural capital, and by lessoning the risk young people are exposed to mentors can disrupt the progress of cumulative inequality. The influence of background or family lineage can be less determining for the young people and the cumulative capital of mentors is more dispersed than within their own families and social networks.

The willingness and attention of mentors to develop expansive and tailored forms of support represents a considerable resource for schools and pupils. Many of the relationships established at the start of the project and referred to above remain in place and their ongoing analysis suggests that the intergenerational dimension of mentoring holds several promising avenues for addressing problems of educational inequality and social mobility. While the data points to the valuable contribution that mentors make to the lives of young people, further research within this project will establish how intergenerational mentoring impacts on the lives of the mentors. Initial work in this area suggests that commitment of volunteers to the project and their continued work with these young people makes a valuable contribution within their own lives. 


\section{Conclusion}

In this research we have shown how intergenerational mentoring disrupts processes which act to reduce the possibility of social mobility for the young people concerned. This is due to two key interconnected factors. Firstly, as largely professional retirees, the mentors provide young people with an essential source of middle-class social and cultural capital that is absent in the young people's own social networks. The 'accumulated capital' of mentors is effectively provided with a new channel for transmission. Secondly as older people, the mentors have both life and career experience to draw on when supporting young people. This form of age specific support provides encouragement, nurtures young people's imagination and realises practical routes to progressing their aspiration. Properly supported and nurtured, intergenerational mentoring is a promising intervention in an area long stagnated. 


\section{$\underline{\text { References }}$}

Abelev, M. S. (2009) Advancing out of poverty: Social class worldview and its relation to resilience. Journal of Adolescent Research, 24, 114-141.

Archer, L., Hollingworth, S., \& Mendrick, H. (2010) Urban youth and schooling. Maidenhead: Open University Press.

Bender Sebring, P., Allensworth, E., Bryk, A., Easton, J., \& Luppescu, S. (2006). The Essential Supports for School Improvement. University of Chicago: Consortium on Chicago School Research.

Bryk, A., Bender Sebring, P., Allensworth, E., Luppescu, S., \& Easton, J. (2010). Organizing Schools for Improvement: Lessons from Chicago. Chicago, IL: University of Chicago Press.

Chambers, T., \& Deller, F. (2011). Chances and Choices of Low-Income Students in Canada and England: A Post-Structuralist Discussion of Early Intervention. In A. Kezar (Ed.), Recognising and Serving Low-Income Students in Higher Education. London \& New York: Routledge.

Coylar, J. (2011). Strangers in a Strange Land: Low-Income Students and the Transition to College. In A. Kezar (Ed.), Recognising and Serving Low-Income Students in Higher Education. New York and London: Routledge.

Cummings, C., Laing, K., Law, J., McLaughlin, J., Papps, I., Todd, L., \& Woolner, P. (2012) Can changing aspirations and attitudes impact on educational attainment? A review of interventions. York: Joseph Rowntree Foundation.

Dannefer, D (2003) Cumulative Advantage/Disadvantage and the Life Course: Cross-Fertilizing Age and Social Science Theory. J Gerontol B Psychol Sci Soc Sci 2003; 58 (6).

DuBois, D. L., Portillo, N., Rhodes, J. E., Silverthorn, N. et al., (2011). How effective are mentoring programs for youth? A systematic assessment of the evidence. Psychological Science in the Public Interest, 12, 57-91. 
Eby, L. T., Allen, T. D., Evans, S. C., Ng, T., \& DuBois, D. (2008). Does Mentoring Matter? A Multidisciplinary Meta-Analysis Comparing Mentored and Non-Mentored Individuals. Journal of vocational behavior, 72(2), 254-267.

Ferraro, K, \& Shippee, P (2009). Aging and cumulative inequality: how does inequality get under the skin? The Gerontologist, 49(3), 334.

Gillies, D., Wilson, A., Soden, R., Gray, S., \& McQueen, I. (2010). Capital, culture and community: understanding school engagement in a challenging context. Improving Schools, 13(1), 21-38.

Gorard, S., Beng, H.S. \& Davies, P. (2012) The impact of attitudes and aspirations on educational attainment and participation York : Joseph Rowntree Foundation.

Hunter Blackburn, L., Kadar-Satat, G., Riddell, S., \& Weedon, E. (2016). Access in Scotland: Access to higher education for people from less advantaged backgrounds in Scotland: The Sutton Trust.

Iannelli, C. (2011). Educational Expansion and Social Mobility: The Scottish Case. Social Policy and Society, 10(02), 251-264.

Kezar, A. (2011). Rethinking Postsecondary Institutions for Low-Income Student Success: The Power of Post-structual Theory. In A. Kezar (Ed.), Recognizing and Serving Low-Income Students in Higher Education New York Routledge.

Kintrea, K., St.Clair, R., and Houston, M. (2011) The influence of parents, places and poverty on educational attitudes and aspirations. York: Joseph Rowntree Foundation.

McArthur, K., Wilson, A \& Hunter, K. (forthcoming 2016). Mentor suitability and mentoring relationship quality: lessons from the Glasgow Intergenerational Mentoring Network. Journal of Community Psychology.

Lynch, S \& Brown, J (2011) 'Stratification and inequality over the life course' in the Handbook of Aging and the Social Sciences, Chapter 8, pp. 105-117. 
Perry, E. and Francis, B. (2010) The social class gap for educational attainment: A review of the literature. London: The RSA

Raffo, C., Dyson, A., Gunter, H., Hall, D., Jones, L., \& Kalambouka, A. (2009). Education and poverty: mapping the terrain and making the links to educational policy. International Journal of Inclusive Education, 13(4), 341 - 358.

Rhodes, J. E. (2005). A theoretical model of youth mentoring. In D. L. DuBois \& M. J. Karcher (Eds.), Handbook of Youth Mentoring (pp. 30-43). Thousand Oaks, CA: Sage Publications, Inc

Roderick, M., Coca, V., Moeller, E., \& Nagaoka. J. (2008). From high school to the future: Potholes on the road to college. . Chicago, IL: The University of Chicago Consortium on Chicago School Research.

Social Mobility and Child Poverty Commission and the Rt Hon Alan Milburn (2014) Breaking the link between demography and destiny in Scotland: Retrieved from https://www.gov.uk/government/speeches/breaking-the-link-between-demography-anddestiny-in-scotland

Social Mobility and Child Poverty Commission (2015) State of the Nation 2015: Social Mobility and Child Poverty in Great Britain. London: Retrieved from https://www.gov.uk/government/uploads/system/uploads/attachment_data/file/485926/State_ of_the_nation_2015_social_mobility_and_child_poverty_in_Great_Britain.pdf.

Savage, M. (2015). Social Class in the 21st Century. London: Pelican.

Wilson, A., \& Hunter, K. (2011, 8 September 2011). Understanding the role of peer group social networks in the attainment of high achieving pupils attending a school serving an area of social disadvantage. Paper presented at the British Educational Research Association, Institute of Education, University of London. 
Wilson, A., Hunter, K., Spohrer, K., Brunner, R., \& Beesley, A. (2014). Mentoring into higher education: A useful addition to the landscape of widening access to higher education? Scottish Educational Review, 46(2), 18-35. 